\title{
Groundwater Seepage Mapping using Electrical Resistivity Imaging
}

\author{
Mohd Hazreek Zainal Abidin ${ }^{1}$, Mohamad Faizal Tajul Baharuddin², \\ Mohd Hafiz Zawawi ${ }^{3}$, Nor'aishah Md $\mathrm{Ali}^{4}$, Aziman Madun ${ }^{5}$, \\ Saiful Azhar Ahmad Tajudin ${ }^{6}$ \\ ${ }^{1,5,6}$ Department of Infrastructure and Geomatic Engineering \\ Universiti Tun Hussein Onn Malaysia, 86400 Batu Pahat, Johor MALAYSIA. \\ ${ }^{2}$ Department of Water and Environmental Engineering \\ Universiti Tun Hussein Onn Malaysia, 86400 Batu Pahat, Johor MALAYSIA. \\ ${ }^{3}$ Department of Civil Engineering \\ Universiti Tenaga Nasional, 43000 Kajang, Selangor MALAYSIA \\ ${ }^{4}$ Geotechnical Department
}

Kumpulan IKRAM Sdn Bhd, 43000 Kajang, Selangor MALAYSIA

ahazreek@uthm.edu.my, ${ }^{\mathrm{a}}$ mdfaizal@uthm.edu.my, ${ }^{\mathrm{C}} \mathrm{MHafiz@uniten.edu.myc}$, dnaishah@ikram.com.my, ${ }^{\mathrm{d}}$ aziman@uthm.edu.my, saifulaz@uthm.edu.my

\section{Keywords: Electrical Resistivity, Groundwater Seepage, 2-D and 3-D Subsurface Image}

\begin{abstract}
In recent years, electrical resistivity method (ERM) has widely being applied as an alternative tool in engineering, environmental and archeological studies. A global image of groundwater seepage problem was difficult to obtained using conventional geotechnical method due to the efficiency of cost, time and result coverage. This study was conducted using electrical resistivity survey in order to investigate the potential of the problematic zone due to the groundwater seepage problem. ABEM SAS 4000 equipment set was used in during the resistivity data acquisition stage. Six (6) resistivity spread lines (SP) were performed across the slopes area using 2-D electrical resistivity imaging. The raw data was processed using RES2DINV and SURFER software for 2-D and 3-D subsurface image. Interpretation of electrical resistivity results was verified using the existing borehole and geochemistry results. Geochemistry results analyses were used Atomic Absorption Spectrometer (AAS) for determining cation and Ion Chromatography (IC) is for anions. Anion elements were studied consists of chloride, bicarbonate, nitrate and sulfate while cation elements consists of sodium, potassium, calcium and magnesium. All the elements were analyzed by using Piper Diagram to determine geochemistry facies in the groundwater. It was found that low resistivity value (ERV) which associated to groundwater $(10 \sim 100 \Omega \mathrm{m})$ can be found starts from the ground surface $(0 \mathrm{~m})$ to a greater $(>10 \mathrm{~m})$ depth of the subsurface profile. The finding of the study water seepage can be categorized as $\mathrm{Ca}-\mathrm{HCO}$ that indicator a typical of shallow fresh groundwater. The finding of the study is important to determine source process of water seepage on that area. This study has successfully demonstrates that the application of ERM with supporting borehole and geochemistry data was able to provide a comprehensive results due to the groundwater leakage detection.
\end{abstract}

\section{Introduction}

Conventional method for groundwater detection such as using drilling technique is weak due to its expensive, time consuming and limited data coverage. Detail forensic study related to groundwater leakage detection requires lots number of drilling in order to obtain high accuracy layout of the profile investigated. As a result, total cost and time of the project will be increased. Those limitations have created some gap in order to determine the most suitable method which able to fulfill several 
considerations which related to cost, time and results quality. In recent years, geophysical techniques such as electrical resistivity, seismic, gravity, magnetic, ground penetration radar, etc. has increasingly adopted in many projects related to engineering and environment due to its ability to be implemented less expensively and more quickly and can cover larger areas more thoroughly [1,2,3,4]. Moreover, it provides a large-scale characterization of the physical properties under undisturbed conditions [3]. Furthermore, site damageability remains minimal and can be negligible although some of it requires ground contact during the data acquisition [5]. As reported by [6], it is important to understand the physical properties associated with the target of interest in order to select the most suitable geophysical method. Furthermore as reported by [7], the standard performance of individual geophysical methods always depends on fundamental physical constraints, e.g. penetration, resolution, and signal to-noise ratio.

Electrical resistivity methods (ERM) are significantly sensitive to variations in earth resistivity property with particular reference to water occurrences [8]. Rapid growth of electronics technology development has greatly improved the electrical resistivity method in term of device and result precision. Nowadays, electrical resistivity tomography has greatly improved the weakness of conventional electrical resistivity sounding in term of survey coverage. Common application of electrical resistivity method (ERM) was related to the groundwater investigation $[9,10,11,8]$. Hence, this study adopted an integration of electrical resistivity method (ERM) in 2-D and 3-D section with drilling and geochemistry information. According to [9], the application of electrical resistivity method (ERM) is vital since it has been proved to be the most successfully tools in groundwater resource mapping as the groundwater movement and existence are largely localized and difficult to predict. This study used drilling data as for verification of the electrical resistivity results. The approach of combination of geophysical application, together with geological control is increasingly acceptance in groundwater exploration [9]. As reported by $[12,13,14,15,16]$, soil resistivity value can be varied due to the variation of basic geotechnical properties such as moisture content, densities, void ratio, porosity and grain size fraction. Moreover as reported by [6], the success at any site investigation works is based on the integration of method.

The main purpose of this study was to map the subsurface problematic zone due to the excessive groundwater seepage which create hazardous to the surrounding area. The results interpreted from the 2-D and 3-D electrical resistivity image is of fundamental importance for the proper zone of the soil and rock saturated with water as the major contribution to the overflow groundwater seepage in the studied area. Furthermore, it also helps in term of decision making to select the most suitable remediation or stabilization techniques within this area.

\section{Methodology}

This study is located in recreational park at Kuala Lumpur, Malaysia. Generally, the site study has mixed topography of undulating valley and surrounded by a developing authority and private building and roads. General geology of site study was formed by Kenny Hill formation as shown in Fig. 1. The formation consists of interbedded sandstone with shale, phylite and slate. In general, the present of this type of rock exhibits geology structures, namely faults, foliations, anticline, syncline, chevron structures, folds and joints. The geological discontinuities from these structures present on the site provided surface water seepage to underground, groundwater carriage, and water storage in rock formation. However, during site investigation, there is no indication of geological structure exposed on the surface. As reported by [17], Kuala Lumpur has nine categories of earth materials such as moderately weathered to fresh quartz veins, moderately to highly weathered metasediments, moderately to slightly weathered schist, moderately weathered to fresh limestone, sand and clay (river alluvium), clayey or silty sand, sandy clay, clay to silty clay and sandy silty clay. 


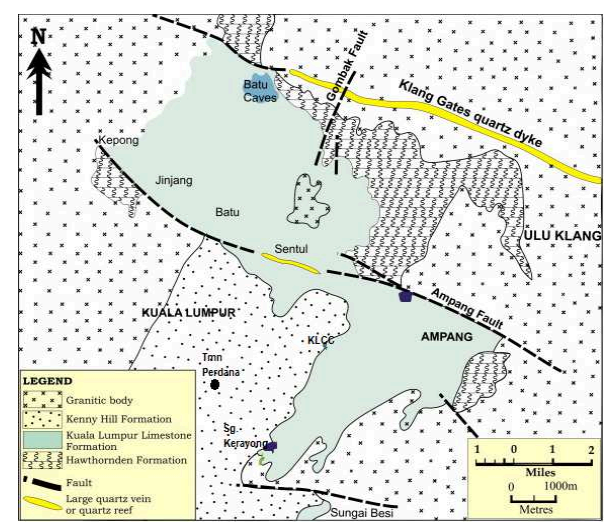

Fig. 1 Geology of the study area [17]

Electrical resistivity survey was conducted using the ABEM Terrameter SAS 4000, combined with ES 10-64 electrode selector. Six (6) resistivity spread lines based on north-south (NS) and west-east (WE) orientation (105-109, 110-113, 117-114, 200-121 and 123-128) were perform across the study area. The electrical resistivity data acquisition setting was given in Table 1. Schlumberger array was used during the data acquisition since it able to provide dense near-surface cover of resistivity data. As reported by [18], the array provides a good vertical resolution and can give a clear image of groundwater and sand-clay boundaries as horizontal structures. Furthermore, the array able to provide greater depth of subsurface profiles within limited spaced area during the resistivity data acquisition (field measurement) stage. Raw data obtained from data acquisition were firstly being processed using commercialize RES2DINV software version 3.59 of [19] to provide an inverse model that approximates the actual subsurface structure. The inversion algorithm of RES2DINV was used to process the data, as proposed by [20] in order to obtain the 2-D resistivity section. The inversion routine used by the program RES2DINV was based on the smooth constrained method due to the target interest (water) and site condition. Finally, 3-D model of the study area was spatially analyzed by interpolation using Kriging technique from SURFER 8 software. This study used Universal Kriging method under Point Kriging technique which has good accuracy due to its point estimation value at the grid node compared to the Block Kriging which only averaging the value at center of the rectangular block on the grid node. The true (inverted 2-D) vertical profiles (Fig.s 2 - 7) were converted into true (inverted 3-D) horizontal profiles, shown in Fig.s $9-13$ for selected depths of interest. This study was performed at least three times the collection of water samples on the slopes and landscape jogging track. Water samples taken were analyzed in the Environmental Engineering Laboratory at Faculty of Civil and Environmental Engineering Universiti Tun Hussein Onn Malaysia using Atomic Absorption Spectroscopy (AAS) and Ion Chromatography (IC). The purpose to perform the AAS and IC tests was to determine the parameters of anion and cation which consists of chloride, sulphate, carbonate, nitrate, magnesium, aluminum, natrium and kalium in order to identify the source of the overflow water seepage. According to [21], water can be categorized as groundwater if the combination of the elements such as chloride, sulphate, carbonate, nitrate, magnesium, aluminum, natrium and kalium was more than $70 \%$. The whole procedure was referred to the APHA (2005) standards [22]. The results of data analysis will be used to determine groundwater facies.

Table 1 2-D Electrical resistivity data acquisition setting

\begin{tabular}{|c|c|c|c|}
\hline No & Spread line reference number & Array & Total survey length, $\mathrm{m}$ \\
\hline 1 & $105-109$ & Schlumberger & 116 \\
\hline 2 & $110-113$ & Schlumberger & 120 \\
\hline 3 & $117-114$ & Schlumberger & 88 \\
\hline 4 & $132-136$ & Schlumberger & 160 \\
\hline 5 & $200-121$ & Schlumberger & 120 \\
\hline 6 & $123-128$ & Schlumberger & 120 \\
\hline
\end{tabular}




\section{Results and Discussions}

Localize layout of the individual 2-D resistivity lines was given in Fig. 2-7 while globalize layout of the study area was given in 3-D image at Fig. 9-13.

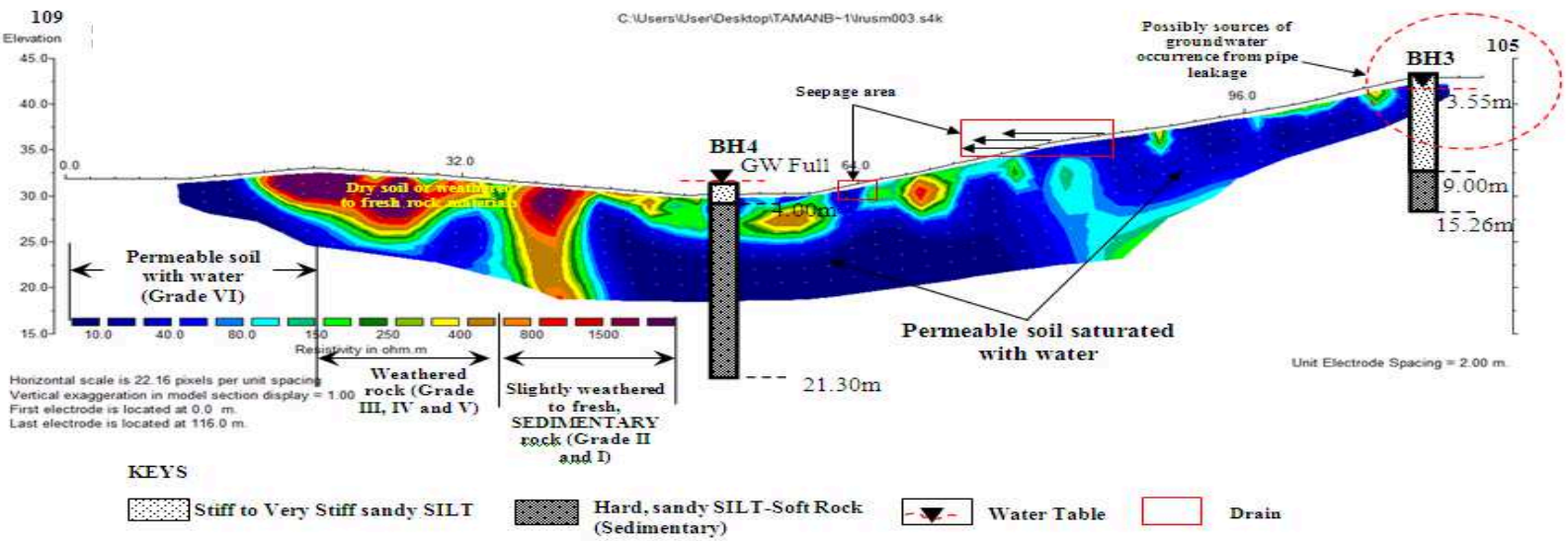

Fig. 2 2-D electrical resistivity image for the spread line 1 (West: 105 - East: 109) at the site

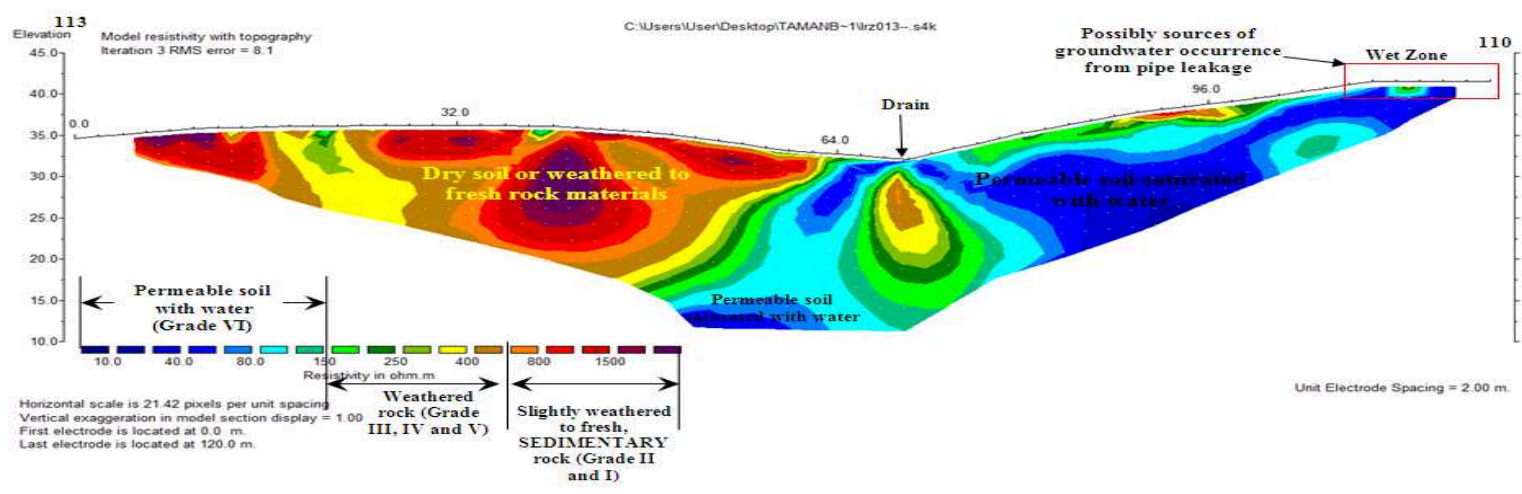

Fig. 3 2-D electrical resistivity image for the spread line 2 (West: 110 - East: 113) at the site

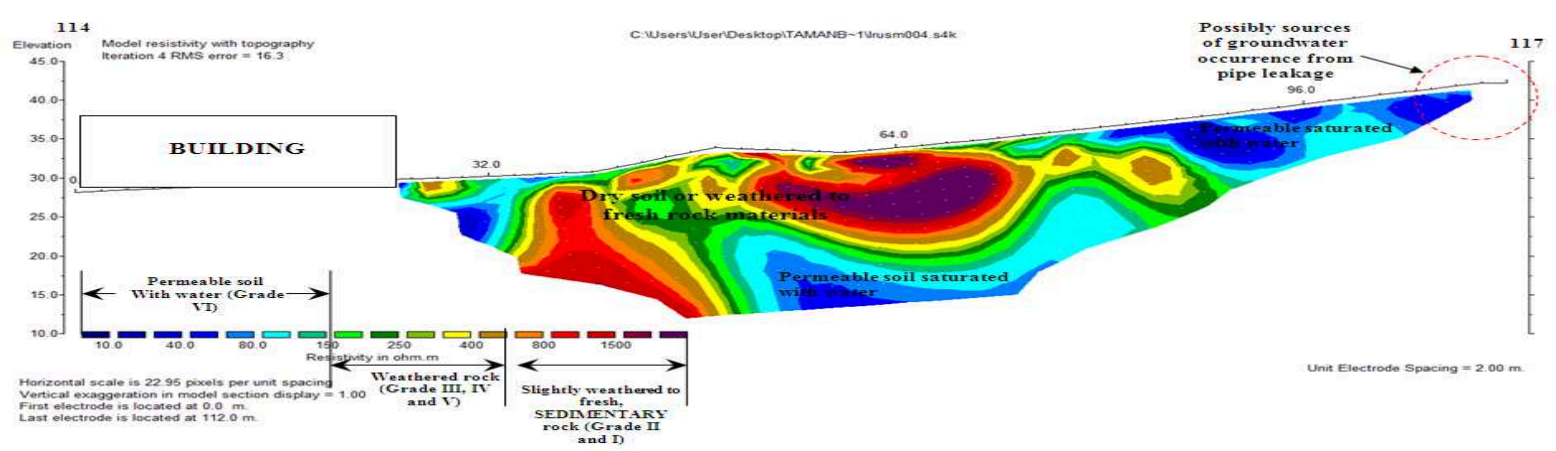

Fig. 4 2-D electrical resistivity image for the spread line 3 (West: 117 - East: 114) at the site

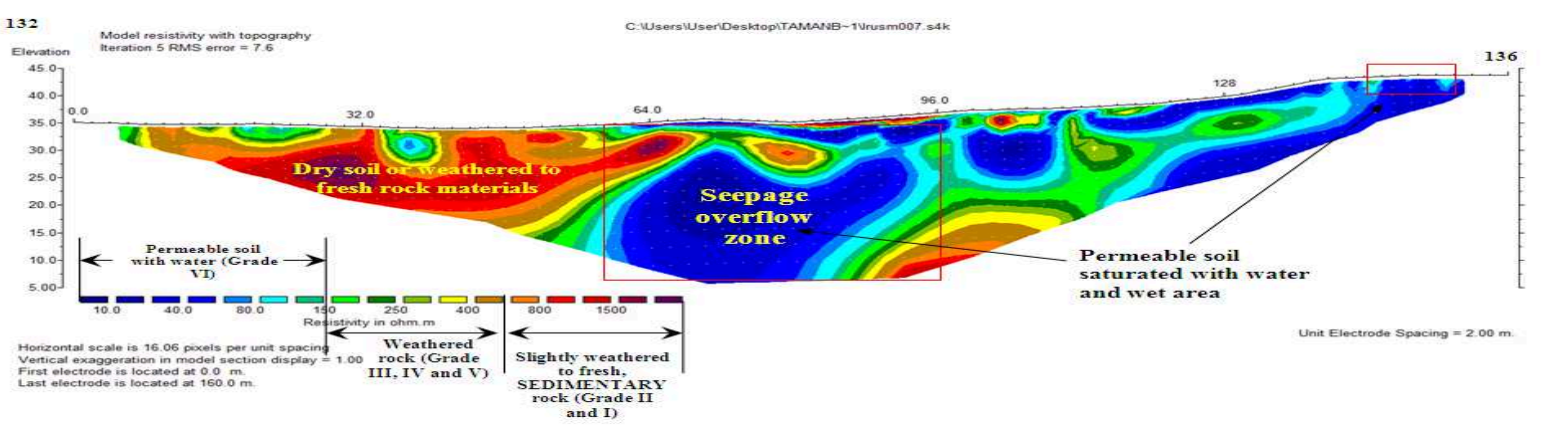

Fig. 5 2-D electrical resistivity image for the spread line 4 (North: 136 - South: 132) at the site 


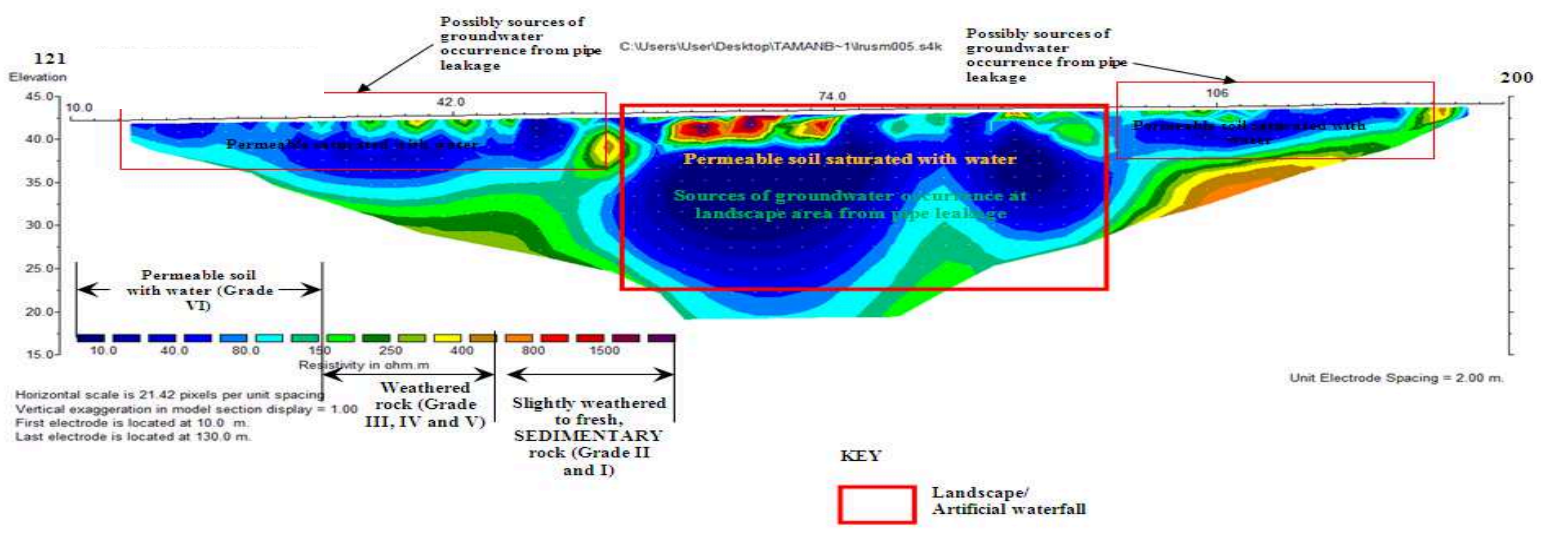

Fig. 6 2-D electrical resistivity image for the spread line 5 (West: 200 - East: 121) at the site

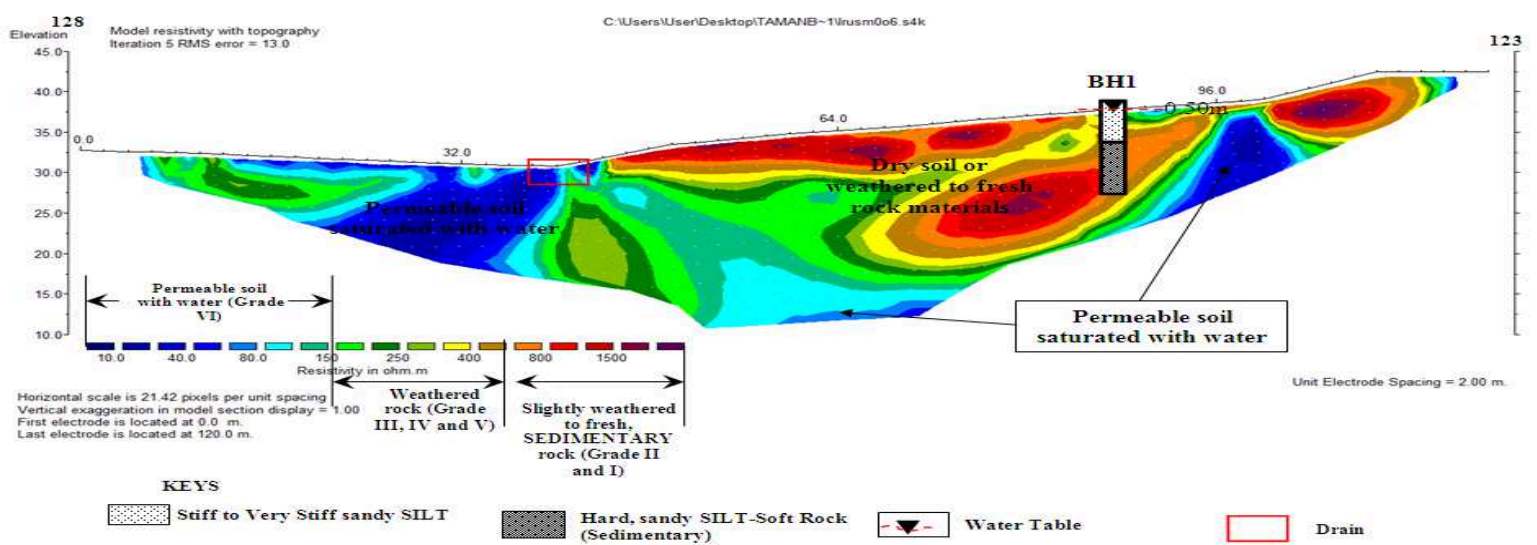

Fig. 7 2-D electrical resistivity image for the spread line 6 (North: 123 - South: 128) at the site

Electrical resistivity value (ERV) was determined by measuring the potential difference at points on the ground surface which caused the propagation of direct current through the subsurface [23]. Electrical resistivity value can be influenced by several factors such as the concentration and type of ions in pore fluid and grain matrix of geomaterials via the process of electrolysis where the current was carried by ions at a comparatively slow rate [24]. According to [2], a soil's electrical resistivity value generally varies inversely proportional to the water content and dissolved ion concentration as clayey soil exhibit high dissolved ion concentration, wet clayey soils have lowest resistivity of all soil materials while coarse, dry sand and gravel deposits and massive bedded and hard bedrocks have the highest ERV. As reported by [25], a decrease of ERV was results from an increased of metal ions or inorganic elements in geomaterials.

Localized image of 2-D electrical resistivity image discussion was focused at three spread lines with particular reference to spread line 1 (105-109), 4 (136-132) and 5 (200-121) while globalize image of the study area will be discussed based on Fig. 9-13. This study has decide to focused on those three (3) lines since it was located at the most critical problematic zone of overflow water seepage. Generally, all of 2-D resistivity image (Fig. 2-7) has shown that the subsurface profile consist of three (3) types of materials with particular reference to permeable residual soil of sedimentary rock with water $(10-100 \mathrm{ohm} . \mathrm{m})$, semi permeable weathered residual soil of sedimentary rock $(100-600$ ohm.m) and slightly weathered to fresh sedimentary rock (600 ohm.m and above). According to [26], water in sediment has a resistivity value of $10-100 \mathrm{ohm} . \mathrm{m}$ while sandy clay has a resistivity value of $100-250$ ohm.m [27]. As reported by [28], resistivity value for sand and gravel with silt, slightly fractured bedrock with dry soil filled cracks and massive bedded and hard bedrock were 305 ohm.m, $305-2438 \mathrm{ohm} . \mathrm{m}$ and $2438 \mathrm{ohm} . \mathrm{m}$ and over respectively.

The location of spread line 1 was conducted exactly above the major seepage zone based on WE orientation. Based on Fig. 2, penetration depth obtained from the analysis was varied from $15-20 \mathrm{~m}$. The image has shown that the profile consist of three types of materials with particular reference to 
permeable residual soil of sedimentary rock with water (Grade VI), semi permeable weathered residual soil of sedimentary rock (Grade III, IV and V) and slightly weathered to fresh sedimentary rock (Grade II and I). Permeable residual soil with water was interpreted by low resistivity value which varied from $10-100 \mathrm{ohm} . \mathrm{m}$. Based on Fig. 2, most of the image has shown low resistivity anomaly thus suggests that this area has a potential to be critical due to the presence of high permeable soil with water. This result was verified with the existing borelog results (BH 3 and $\mathrm{BH} 4)$. According to the $\mathrm{BH} 3$ and 4 results, soil with water was starts detected at depth of $3.55 \mathrm{~m}$ and $0.00 \mathrm{~m}$ respectively from the ground surface. Furthermore, the presence of overflow groundwater seepage (Fig. 9) was obviously being observed during the field observation which strongly confirmed the resistivity result interpreted. Fig. 2 also revealed that the subsurface profile consist of semi permeable weathered (100 - $600 \mathrm{ohm} . \mathrm{m})$ and hard materials (600 and above) which associated to sedimentary rock. The resistivity value of $150-600 \mathrm{ohm} . \mathrm{m}$ was interpreted as semi permeable weathered of sedimentary rock consists of material form Grade III, IV and V. Based on BH 3 and 4 results, heterogeneous weathered materials such as sandy clay and gravelly silt can be found at $3 \mathrm{~m}$ depth from ground surface thus has confirmed the resistivity result interpreted. Finally, resistivity value of 600 and above was interpreted as slightly weathered to hard rock material.

Spread line 4 was performed perpendicular to the spread line $1-3$ based on NS orientation. The aim of this line was to map the distribution of groundwater in the slope upper zone which can be observed during the field observation. Based on Fig. 5, penetration depth obtained from the analysis was varied from 30 to $35 \mathrm{~m}$. Three types of materials as stated previously were detected within the profile. It was found that major distribution zone of low resistivity value $(10-100 \mathrm{ohm} . \mathrm{m})$ due to the existing of permeable soil with water was located at center to the right flank of the image as given in Fig. 5. The rest of the subsurface profile consist of semi permeable weathered $(100-600 \mathrm{ohm} . \mathrm{m})$ and slightly weathered to fresh sedimentary rock (600 ohm.m and above) which located at left hand side of the resistivity image.

Spread line 5 was performed parallel to the existing road based on WE orientation. The aim of this spread line was to map the water distribution at the upper zone along the slope face as shown in Fig. 6. Excessive water seepage can be observed on site which continuously comes out from the slope thru the structure cracking. Hence, this condition has caused the near pedestrian walk to be slippery thus posed some danger to the pedestrian walk user. The resistivity image has shown that the penetration depth obtained from the analysis was varied from 20 to $25 \mathrm{~m}$ as shown in Fig. 7. Three types of materials as stated previously were detected within the profile. It was found that the major distribution zone of low resistivity value $(10-100 \mathrm{ohm} . \mathrm{m})$ due to the permeable soil with water was located at center to the both flank of the image as shown in Fig. 6. The rest of the subsurface profile consist of semi permeable weathered $(100-600 \mathrm{ohm} . \mathrm{m})$ and slightly weathered to fresh sedimentary rock (600 ohm.m and above). The resistivity image also suggests that this area was critical due to the low resistivity value domination which associated to weak materials such as permeable soil with water.

Global layout of the problematic study area was presented in 3-D image in Fig. 8-13. Based on those Fig.s, permeable soil with water, semi permeable weathered material and impermeable rock material was represent by blue, green and red anomaly respectively. The 3-D image has revealed that the problematic zone due to permeable soil with water (blue anomaly) was dominantly located at the top to middle portion of the slope structure. This finding has suggests that the overflow water seepage which occurred within this area was come from the top of the slope area due to the regional groundwater flow. Hence, the pore water pressure in slope permeable material will be increased due to the excessive water thus creating overflow groundwater seepage. In addition, the images also reveal that the groundwater seepage which occurred on the slopes was located at the soil contrast boundary as referred to permeable layer (sand material) and semi permeable to impermeable layer (clay and silt material) as shown in Fig. 9-13. This interpretation was supported by geological condition in this area which composed of interbedded sandstone and shale derived from Kenny Hill formation. Finally, the 3-D resistivity distribution result in Fig. 13 has shown that water anomaly was still can be detected at more than $10 \mathrm{~m}$ depth from the ground surface. 
Based on geochemistry results from Fig. 14 and 15, the content of groundwater geochemical elements was highly concentrated by bicarbonate, sulphate and chloride. The rest of the parameters tested are has shown other common elements which can be found in groundwater. The range of high bicarbonate content can be attributed to the flow of groundwater through the limestone formation located in the heart of Kuala Lumpur as shown from the geological map in Fig. 1. However, high concentration of sulphate and chloride recorded was possibly due to several uncertainties factors such as geological process or human activity that require some further detail study afterwards. Detail relationship between levels of groundwater with geochemistry concentration was unable to carry out since water sampling was only being performed at the overflow seepage occurrences due to the limitation of study which related to cost and time. Furthermore, this study was still in the early stages which focus mainly to identify the source of the overflow groundwater seepage within this area. However in near future, detail study regarding the relationship between groundwater levels with geochemical concentration was good to performed in order to obtained comprehensive results and conclusion.

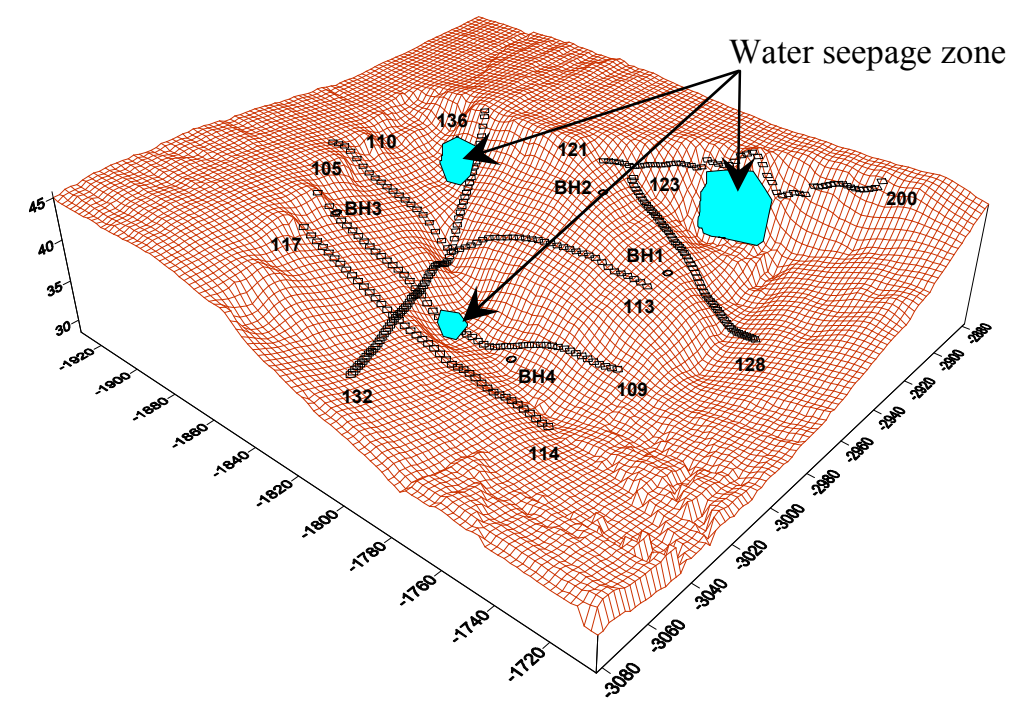

Fig. 8 Topography, resistivity lines and groundwater occurrences in study area

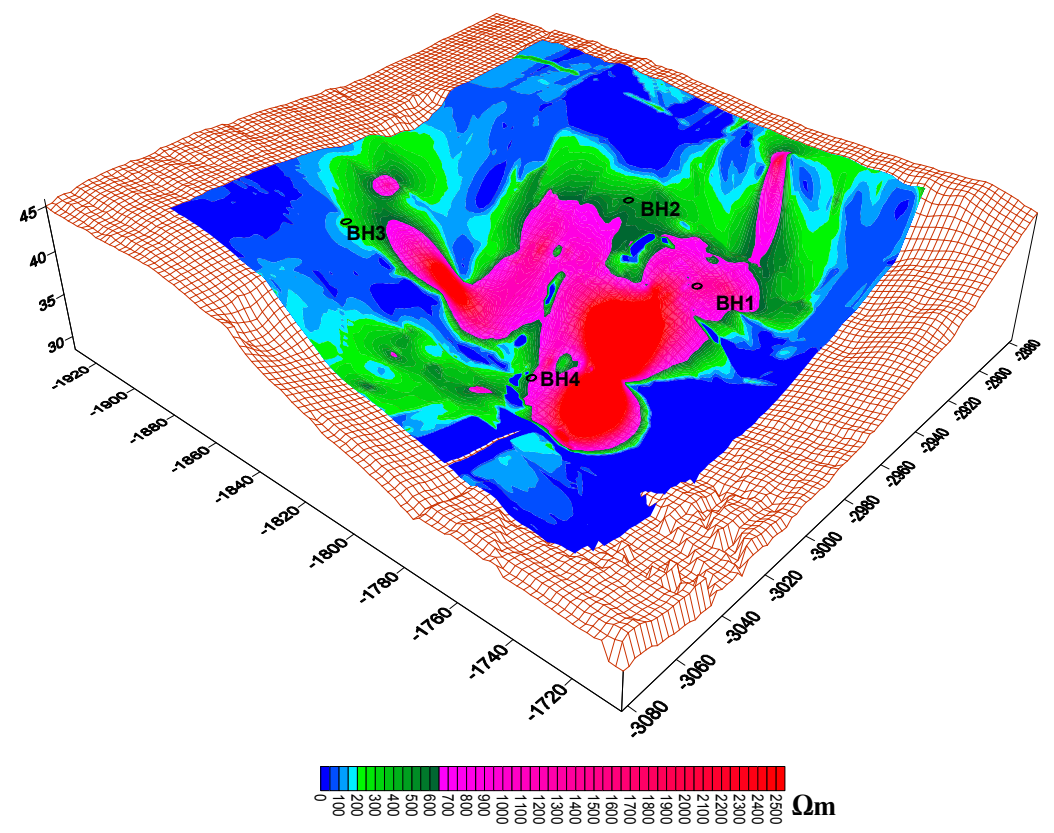

Fig. 9 3-D resistivity image at depth 1 meter from ground surface 


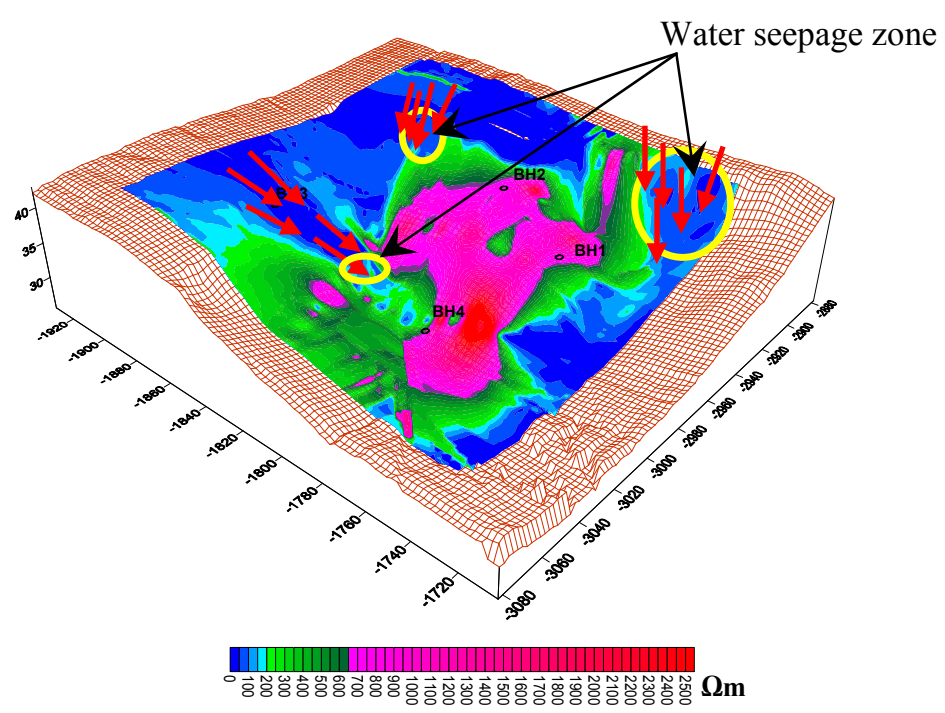

Fig. 10 3-D resistivity image at depth 3 meter from ground surface
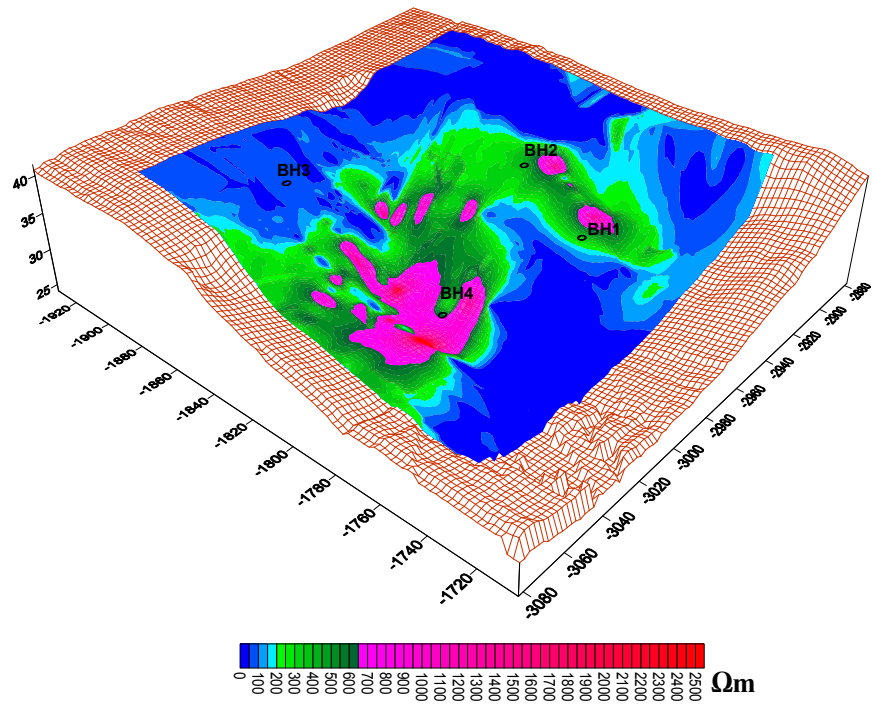

Fig. 11 3-D resistivity image at depth 4 meter from ground surface

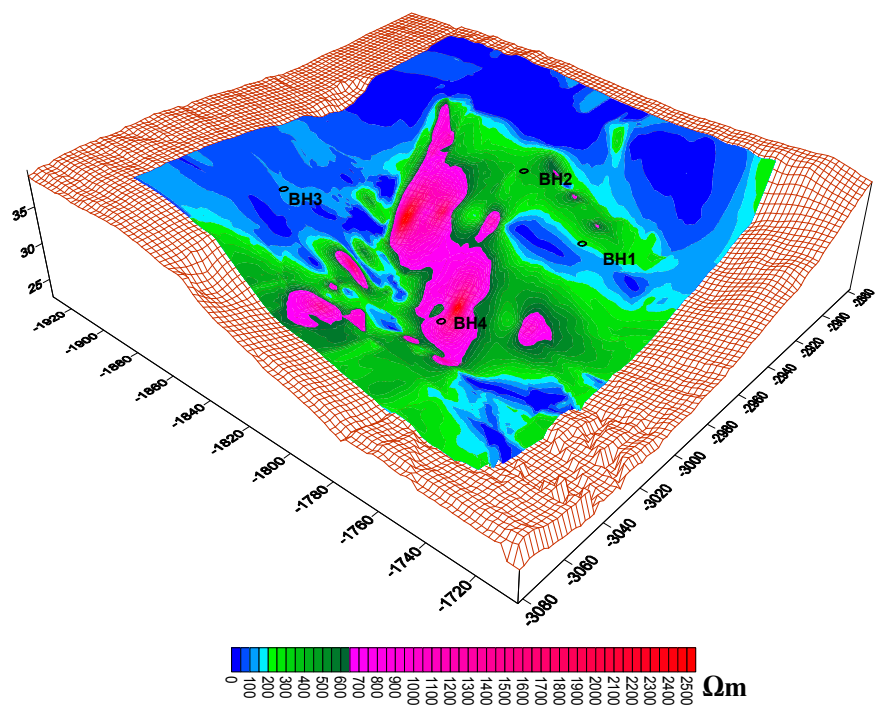

Fig. 12 3-D resistivity image at depth 6 meter from ground surface 


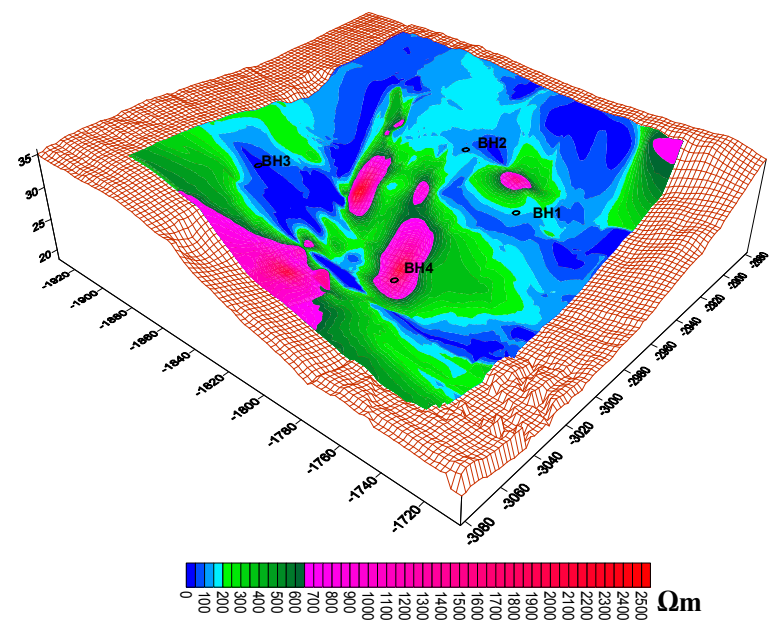

Fig. 13 3-D resistivity image at depth 10 meter from ground surface

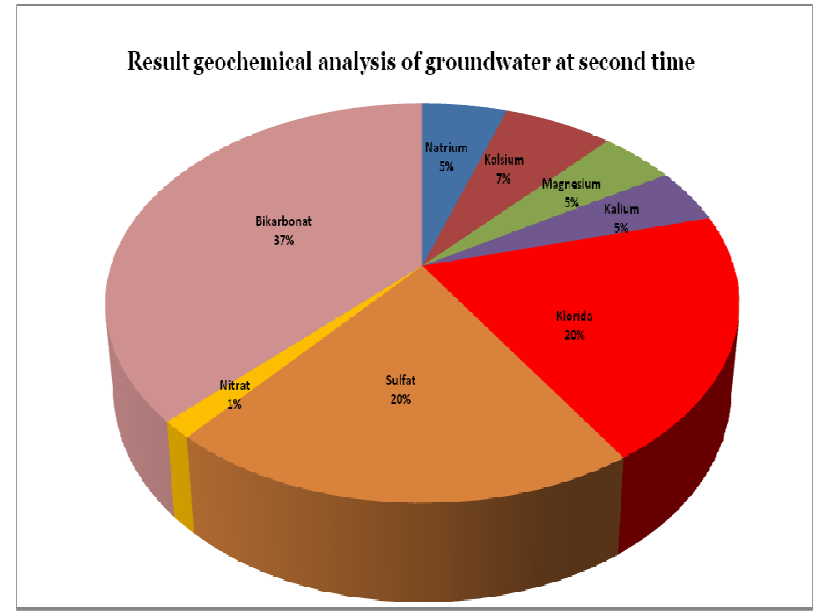

Fig. 14 Result at first time analysis

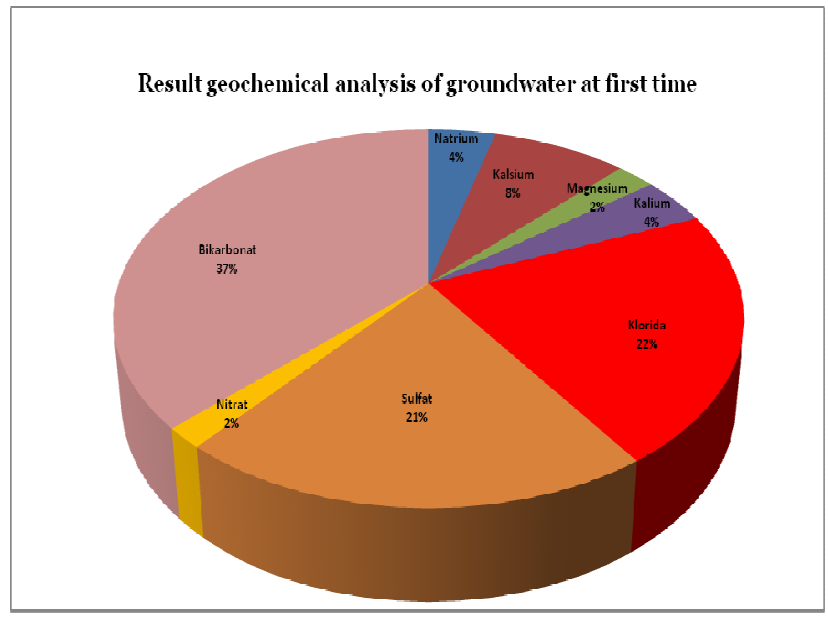

Fig. 15 Result at second time analysis

\section{Conclusion}

The 2-D and 3-D resistivity imaging was successfully performed due to subsurface geomaterials mapping with particular reference to groundwater seepage problem. The 2-D and 3-D resistivity images has provide the lithology information of the permeable soil with water (Grade VI), semi permeable weathered residual soil of sedimentary rock (Grade III, IV and V) and slightly weathered to fresh sedimentary rock (Grade II and I) presence at the studied area. The permeable soil with water showed the resistivity value ranges from 10-100 ohm.m. Meanwhile, semi permeable weathered residual soil of sedimentary rock (Grade III, IV and V) was found by the resistivity value of 150-600 ohm.m. The resistivity value ranges from $600-2500 \mathrm{ohm} . \mathrm{m}$ was found to be dry or hard materials which associated to slightly weathered to fresh sedimentary rock. Based on resistivity interpretation and water chemistry, the occurrence of groundwater seepage in the studied area was due to the groundwater flow within this area. Furthermore, direct infiltration from precipitation and water seepage through geologic structure discontinuities has greatly contribute to the excessive water within the subsurface profile. The result was able to contribute preliminary information for the suitable remediation and stabilization techniques at the problematic study area. This study has shown that the integration of 2-D and 3-D electrical resistivity imaging which supported by borehole and geochemistry information was applicable being applied for groundwater investigation efficiently in term of time, cost and data coverage. 


\section{Acknowledgements}

This work was funded by Universiti Tun Hussein Onn Malaysia (FRGS Vot 1061). Many thank are due to all research members for their tremendous guidance and cooperation.

\section{References}

[1] R. Khatri, V.K. Shrivastava and R. Chandak (2011): Correlation between vertical electric sounding and conventional methods of geotechnical site investigation, International Journal of Advanced Engineering Sciences and Technologies, 4, 042-053.

[2] C. Liu, J.B. Evett: Soils and Foundation (Pearson International, Singapore 2008).

[3] A. Godio, C. Strobbia and G. De Bacco: Geophysical characterisation of a rockslide in an alpine region, Engineering Geology, 83, (2006): 273-286.

[4] P. Cosenza, E. Marmet, F. Rejiba, Y. Jun Cui, A. Tabbagh and Y. Charlery (2006): Correlations between geotechnical and electrical data: A case study at Garchy in France, Journal of Applied Geophysics, 60, 165-178.

[5] C.R.I. Clayton, M.C. Matthews and N.E. Simons: Site Investigation (Blackwell Science Ltd, UK (1995).

[6] R.C. Benson, L. Yuhr and R.D. Kaufmann (2003): Some considerations for selection and successful application of surface geophysical methods, The 3rd International Conference on Applied Geophysics, Orlando, Florida.

[7] H.J. Mauritsch, W. Seiberl, R. Arndt, A. Romer, K. Schneiderbauer and G. P. Sendlhofer (1999): Geophysical investigations of large landslides in the Carnic Region of Southern Austria, Engineering Geology, 56, 373-388.

[8] R. Owen, O. Gwavava and P. Gwaze (2006): Multi-electrode resistivity survey for groundwater exploration in the Harare greenstone belt, Zimbabwe, Hydrogeology Journal, 14, 244-252.

[9] M. E. Juanah, S. Ibrahim, W. Sulaiman and P. Latif (2012): Groundwater resources assessment using integrated geophysical techniques in the southwestern region of Peninsular Malaysia, Arabian Journal of Geosciences, 1-16.

[10]M. Metwaly, G. El-Qady, U. Massoud, A. El-Kenawy, J. Matsushima, and N. Al-Arifi (2010): Integrated geoelectrical survey for groundwater and shallow subsurface evaluation: case study at Siliyin spring, El-Fayoum, Egypt, International Journal of Earth Sciences, 99, 1427-1436.

[11] S. Sultan, S. Mansour and F. Santos (2008): A hydrogeophysical investigation of the Ain Mousa area, near Cairo, Egypt, Bulletin of Engineering Geology and the Environment, 67, 111-117.

[12] M.H.Z. Abidin, R. Saad, F. Ahmad, D.C. Wijeyesekera and M.F.T. Baharuddin (2014): Correlation analysis between field electrical resistivity value (ERV) and basic geotechnical properties (BGP), Soil Mechanics and Foundation Engineering, 51, 117-125.

[13] M.H.Z. Abidin, F. Ahmad, D.C. Wijeyesekera and R. Saad (2014): The influence of basic physical properties of soil on its electrical resistivity value under loose and dense condition, Journal of Physics: Conference Series, 1-13.

[14] M.H.Z. Abidin, F. Ahmad, D.C. Wijeyesekera and R. Saad (2014): Small soil embankment electrical resistivity value on its array, moisture content and density influences, International Journal of Geology, 8, 9-18. 
[15] M.H.Z. Abidin, F. Ahmad, D.C. Wijeyesekera, R. Saad, and M.F.T. Baharuddin (2013): Soil resistivity measurements to predict moisture content and density in loose and dense soil, Applied Mechanics and Materials, 353-356, 911-917.

[16]M.H.Z. Abidin, D.C. Wijeyesekera, R. Saad and F. Ahmad (2013): The influence of soil moisture content and grain size characteristics on its field electrical resistivity, Electronic Journal of Geotechnical Engineering, 18/D, 699-705.

[17] S.S. Mansor (2003): Analysis of site classification for Kuala Lumpur's ground assessment, Unpublished Master Thesis, Universiti Sains Malaysia.

[18]U. Hamzah, R. Yaacup, A. R. Samsudin and M. S. Ayub (2006): Electrical imaging of the groundwater aquifer at Banting, Selangor, Malaysia, Environmental Geology, 49, 1156-1162.

[19] M.H. Loke, I. Acworth and T. Dahlin (2003): A comparison of smooth and blocky inversion methods 2-D electrical imaging surveys, Exploration Geophysics, 34(3), 182-187.

[20] M.H Loke and R.D Barker (1996): Rapid least squares inversion of apparent resistivity pseudosection using a quasi-Newton method, Geophysical Prospecting, 44(3), 131-152.

[21]R.A. Freeze and J.A. Cherry: Groundwater, Prentice Hall Inc., New Jersey (1979).

[22]APHA: Standard methods for the examination of water and wastewater (21st edn). American Public Health Association, Washington, DC(2005).

[23]H.R. Burger, A. F. Sheehan and C. H. Jones: Introduction to Applied Geophysics, W.W. Norton \& Company (2006).

[24]D.H. Griffiths and R.F. King: Applied Geophysics for Geologist and Engineers The Element of Geophysical Prospecting, Pergamon Press, Oxford (1981).

[25] Y. Jung, Y. Lee and H. Ha: Application of electrical resistivity imaging techniques to civil and environmental problems, Use of Geophysical Methods in Construction (2000).

[26] W.M. Telford, L. P. Geldart and R. E. Sheriff: Applied Geophysics, Cambridge University Press., Cambridge (1976).

[27]T. S. Lee: Slope Stability and Stabilization Methods, John Wiley \& Sons, Inc. New York (2002).

[28]D.F. McCarthy: Essentials of Soil Mechanics and Foundations Basic Geotechnics, Pearson International Edition, New Jersey (2007). 